\title{
The research works of Coulomb and Amontons and generalized laws of friction
}

\author{
Elena POPOVA ${ }^{1, *}$, Valentin L. POPOV ${ }^{1,2}$ \\ ${ }^{1}$ Institute of Mechanics, Technische Universität Berlin, 10623, Berlin \\ ${ }^{2}$ National Research Tomsk State University, 634050 Tomsk, Russia \\ Received: 29 January 2015 /Accepted: 11 February 2015 \\ (C) The author(s) 2015. This article is published with open access at Springerlink.com
}

Abstract: The paper is devoted to the contributions of Coulomb and Amontons to the physics of friction from the viewpoint of current discussions and attempts to formulate generalized laws of friction.

Keywords: static friction; sliding friction; kinetics of friction; material dependency; history of science

\section{Introduction}

It is often stated that it was Leonardo da Vinci [1] who made the first significant contribution to the physics of friction by formulating the main "laws of dry friction": (a) Friction is proportional to weight, (b) friction does not depend on the contact area, and (c) the ratio of friction to weight is approximately $1 / 4$. However, these conclusions were written in his personal notebooks and do not seem to have had any impact on the science and engineering of that time. The first study of friction which was broadly publicly discussed seems to be the memoir of Amontons of 1699 [2] (Figs. 1(a) and 1(b)).

Right at the beginning of his memoir, Amontons formulates the following four "laws of friction" (Fig. 1(b)):

- First, the resistance caused by friction increases/ decreases in proportion to the pressure.

- Secondly, the resistance caused by friction is the same for iron, copper, lead and wood as long as they are lubricated with a grease.

- Thirdly, this resistance is roughly equal to one-third of pressure.

- Fourth, this resistance does not depend on velocity and other conditions.

*Corresponding author: Elena POPOVA.

E-mail: elena.popova@tu-berlin.de (a) 206 MEMOIRES DE L'A CAdEMIE ROYALE

les Rouës a l'horizon. Mais la premiere n'a ni frottement ni perte d'eau, \& ainfi à tout prendre elle eft la meilleure. On peut avec les deux tirer jufqu'à s000. muids d'eau par heure.

$D E L A R E S I S T A N C E$ CAUSE'E DANS. LES MACHINES,

Tant par les frottemens des parties qui les compofent, que par la roideur des cordes qu'on y employe, of la maniere de calculer l'un er l'autre.

Par M. A M ON ToN

19. Decem. T E grand ufage que tous les Arts font obligés de faire L des machines, eft une preuve convaincante de leur abloluë néceffité ; ainfi fans perdre tems à établir autrement cette verité, on fe contentera de dire icy, que fí le nom de Machine eft quelquefois pris en mauvaife part, \& s'il devient quelquefois méprifable, ce n'eft en partie qu'à caufe que le peu de régles que nous avons dans les Mécaniques ne fuffirent pas toújours pour prévoir certainement l'effet oue les Machines au'on nroierte doivent nro-

(b) Primò, Que la réfiftance caufée par le frottement n'augmente \&o ne diminuë qu'd proportion des preflions plus ou moins grandes fuivant que les parties qui frottent ont plus ôs moins d'é: senduè.

Secundò, Que la réffftance caufée par les frottemens eft à peu près la même dans le fer, dans le cuivre, dans le plomb, dans

\footnotetext{
DES S C I E NCES. 209 le bois, en quelque maniere qu'on les varie, lor/que ces matieres font enduites de vieux-oingt.

Tertiò, Que.cette réfftance eft à pers près égale aul tiers de la prefjion: A ces remarques il convient encore ajoûter cette quatriéme, que ces réfiflances font entre elles en raifon compofées des poids ou preffions des parties qui frottent, des tems or des. vîtefes de leur mouvement.
}

Fig. 1 Excerpts from the memoir of Amontons "De la resistance cause'e dans les machines" of 1699: (a) title page, and (b) formulation of the "laws of friction". 
This is the classical formulation of the law of dry friction as it can be found in most contemporarily school books on physics. The work of Amontons became widely known and had a great impact on the engineering praxis. The proportionality of the force of friction to the normal force is deservedly called "Amontons' law". The great merit of Amontons was the simplification of the very complex phenomenon of dry friction. His law of friction was of "rude empirical nature", because at that time there were no adequate ideas which could lead to a proper "derivation" or theoretical understanding of this law. Even today, very emotional discussions about the physical nature of the law of Amontons arise periodically (see, e.g., Refs. [3] and [4]). At the same time, one should not forget that the generality of "Amontons' law" is owed to its extreme "roughness": It is a zeroth-order approximation which describes reality only qualitatively, but becomes incorrect as soon as more detailed information about friction is needed. A much better understanding of the friction phenomenon in its entire complexity is due to the works of Charles Augustin Coulomb, the analysis of whose works forms the central theme of this paper.

\section{Coulomb's works on friction: A short historical overview}

In addition to the original works of Coulomb, the most complete historical essay on his life and work can be found in the book of Gillmor [5]. In the present historical review we follow these two sources.

The first scientific work of Coulomb was his memoir of 1773 "On an application of the rules of maximum and minimum to some statical problems, relevant to architecture" [6] (for English translation see Ref. [7]). In the first sentence of his memoir, Coulomb writes: "The object of this paper is to determine, so far as a mixture of calculation and physical principles will allow, the effect of friction and of cohesion in some problems of statics". In this work, Coulomb considered only static friction. He writes: "Friction and cohesion are not active forces like gravity, which always exerts its full effect, but only passive forces; theses two forces can be measured by the limits of their strength ... I will assume here that strength due to friction is proportional to compressive force, as was found by Amontons, although for large bodies friction does not follow exactly this law. According to this assumption, it is found that friction for bricks is three quarters of the compressive force ..." ([6], Section IV)).

However, the focus of this first memoir of Coulomb was not on friction but on the mechanics and strength of materials. These studies Coulomb carried out on Martinique, where he was in charge of building the new Fort Bourbon [5]. From the viewpoint of the form of presentation and the mathematical means used, this first note of Coulomb is very similar to modern text books on the mechanics of materials. For example, when treating the strength of columns, he first considers differently oriented sections of the column under the assumption of cohesion that does not depend on the compressive force. He finds the section with the maximum tangential stress by setting the derivative of the stress with respect to the angle to zero and comes to the conclusion that the columns will be destroyed due to shear along faces oriented at $45^{\circ}$ to the axis of the column. He then generalizes his treatment by introducing a shear strength that has a cohesive and frictional components, the latter being proportional to the compressive force. In contemporary notation we would write his assumption as

$$
\tau=\tau_{0}+\mu \sigma_{\mathrm{N}}
$$

Here, $\tau$ is the tangential stress, $\tau_{0}$ is tangential strength at zero normal stress, $\sigma_{\mathrm{N}}$ the normal stress in the given section, and $\mu$ is the "internal coefficient of friction", which can be determined from independent experiments and was estimated by Coulomb to be $\mu \approx 3 / 4$ for the bricks which he used in Martinique. Equation (1) is very widely used in the mechanics of granular media and soils (see, e.g., Ref. [8], Chapter 20) and is historically correctly called Coulomb fracture criterion. It is interesting to note that this "twocomponent" law of strength/friction was also exploited by Coulomb in his later works. Thus, he considered "strength" and "static friction" from the same point of view. The difference was only in the relative importance of cohesive and frictional contributions.

In 1779 Coulomb was transferred to Rochefort to participate in the construction of a fort made entirely from wood near Ile d'Aix, where he had the possibility 
to use a laboratory for his investigations. During this period Coulomb carried out a series of experiments devoted to the study of friction, the results of which were presented in the memoir "The theory of simple machines" - the seminal work in the study of friction. In 1781 Coulomb received a prize of the Parisian Academy of Sciences for this work. This was already the second Academy prize won by Coulomb. In the following, we will analyze some of results of this work following the later edition of 1821 [9].

In later years, Coulomb returned many times to frictional studies. Thus, in July 1789 he presented his study on friction in tip pivots and rolling friction [10]. In 1780 he also studied friction in fluids [11]. He found, correctly, that the force of friction in fluids is proportional to the velocity at very small velocities and to the square of velocity at larger velocities, and does not depend on the roughness of the solids that are in contact with the fluid. In the case of fluids he also suggested that there is some "cohesive" part of friction which does not depend on velocity. However, he could not determine it experimentally. It is interesting to note, that this intuition proved to be partially correct, since, in some "fluids", one really can identify both static and viscous friction parts (e.g., in soft elastomers or grease lubrication).

We do not consider here the works of Coulomb about the torsion of wires, his famous torsional balance and the works on electricity and magnetism, which earned him his undying glory.

(a) THÉORIE

DES

\section{MACHINES SIMPLES,}

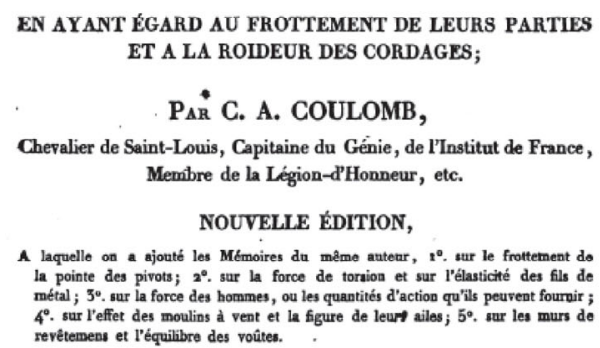

\section{Main findings of Coulomb concerning dry friction}

Coulomb starts his main memoir on friction with this introductory statement: "Amontons seems to be the first author who tried to evaluate the friction and stiffness of the strings for computing machines. He believed that he had found through his experiments, that the extent of the surfaces does not influence friction, which thus depends only on the pressure of the contacting parts: He concludes that in all cases, the friction is proportional to the pressure." [9] (Fig. 2(b)). Following this, he concludes that other investigations show Amontons' law to be inexact and that a detailed investigation is of importance. Coulomb investigated the force of friction as function of many factors, which Gillmor [5] summarizes in the following list:

1. materials constituting the reacting bodies;

2. surface conditions (polished, rough);

3. lubricants (oil, tallow, tar, axle grease, water);

4. weight (normal force);

5. surface area of contact;

6. deformation or cohesion effects due to time of repose;

7. geometric orientation of interacting surfaces (parallel or perpendicular to wood grain, etc.);

8. velocity of surface motion;

9. deformation due to geometry of surfaces (shape of interacting surfaces - planar, pointed, curved);

10. temperature and humidity;

(b)

1. M. Amontons, dans les Mémoires de l'Académie des Sciences pour 1699 , paraît ètre le premier auteur qui ait cherché à évaluer le frottement et la roideur des cordes dans le calcul des machines. Il crut trouver, par ses expériences, que l'étendue des surfaces n'entrait pour rien dans les frottemens, dont la mesure dépendait uniquement de la pression des parties en contact : il en conclut que, dans tous les cas, le frottement est proportionnel aux pressions.

Fig. 2 The main work of Coulomb devoted to friction: "Théorie des machines simples", Parisian edition of 1821: (a) title page, (b) the beginning of the memoir. 
11. state of motion (uniform or impulsive);

12. air pressure.

We would like to stress that the investigation by Coulomb is an example of excellent experimental work, which apparently was not guided by any purely theoretical ideas or simple rules. He "honestly" studied the force of friction under various conditions and tried to present the results in a form that can be used by physicists and engineers.

\subsection{Dependence of the static force of friction on the contact time}

Let us start with his studies of static friction. Coulomb knew that the static force of friction does depend on the time elapsed from the first moment of contact. He therefore never gives the value of the static force of friction but three or four values: e.g. after $1 / 2 \mathrm{~s}, 2 \mathrm{~s}$, "10 $\mathrm{s}$ and $1 \mathrm{~h}$ " (see Fig. 3). The last statement means that the force of friction reaches its stationary level after $10 \mathrm{~s}$ and does not change further.

\subsection{Dependence of the sliding force of friction on the normal force}

Coulomb also studied dependence of the sliding coefficient of friction on the normal force. Note that Coulomb himself never used the notion "coefficient of friction" but he often presents the relation of the normal force to the force of friction, the "inverse coefficient of friction" (see, e.g., Fig. 4). We can see that by increasing the normal force by a factor of 35 , Coulomb observes a decrease of the coefficient of friction almost by a factor of two. In other examples, he observed even stronger dependency on normal force.

\section{EXPÉRIENCE.}

Le traîneau chargé, son poids compris, de 50 liv. Après $\frac{1}{3}^{\prime \prime}$ de repos, le frottement a été trouvé de ${ }_{2} 5$ liv. Après $\mathbf{2}^{\prime \prime}$ de repos. . . . . . . . . . . . 3o Après $10^{\prime \prime}$ et uneheure. . . . . . . . . . 36 VIII EXPÉRIENCE.

Le traîneau chargé, son poids compris, de 450 liv. Après $\frac{1}{2}$ de repos. . . . . . . . . . 256 liv. Après 2 " de repos. . . . . . . . . . . 286 Après une minute et une heure. . . . . . . . 284

Fig. 3 Typical presentation of data about the force of friction in the "Théorie des machine simples". The values for each normal force are given for different waiting times up to the time of saturation [9].

\section{Frottement d'une surface d'un pied carré, chargé des} pressions suivantes.

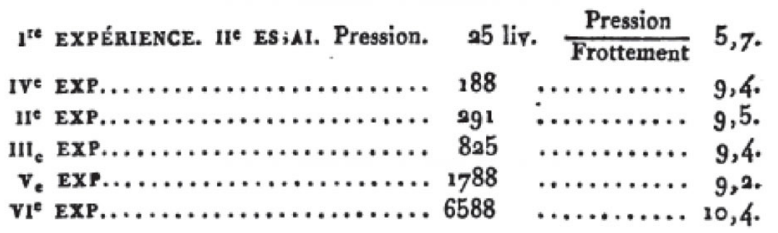

Fig. 4 Dependence of the inverse coefficient of friction on the normal force. "Friction of a surface of a square foot, and the following loads" [9].

\subsection{Dependence of the force of friction on the contact size}

Coulomb finds that in most cases the force of friction is not very sensitive to the contact area, as already found by Amontons. However, in some cases, he found a pronounced dependence, as one can see in Fig. 5.

\subsection{Dependence of other parameters}

As already mentioned above, Coulomb also studied the influence of many other factors and tried to summarize them in a form which can be used by engineers. In most cases he managed to formulate simple "two-term" laws of the same type as Eq. (1) where the first term described the main constant contribution and the second one a relatively weak dependence on the variable in question (time, normal force, velocity, size of the contact and so on).

From today's point of view, it is interesting to note that the main findings of Coulomb about the dependence of the force of friction on the normal force and

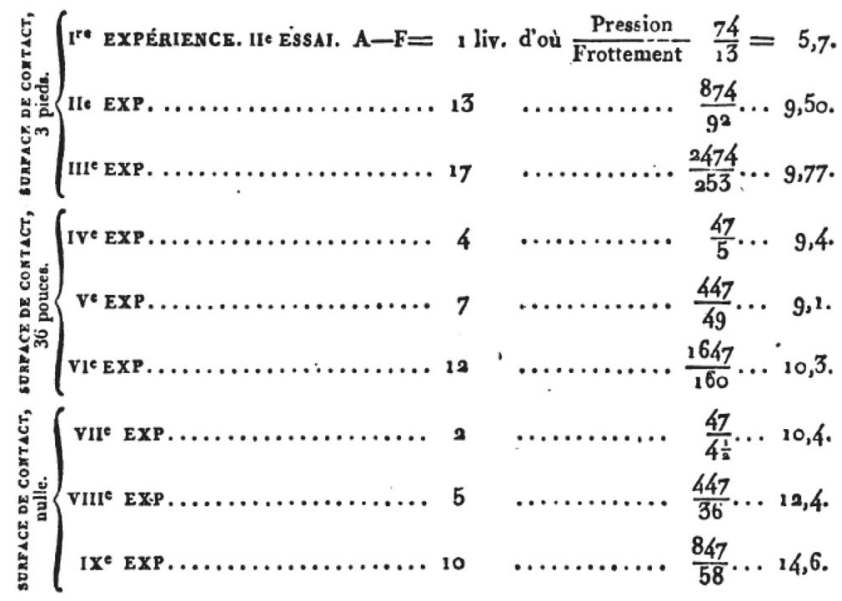

Fig. 5 Dependence of the inverse coefficient of friction on the contact area, an example of Coulomb's data [9]. 
the apparent contact size can be summarized as follows: The coefficient of friction for the given frictional pair becomes larger, if the indentation depth of the roughness of two bodies becomes smaller (smaller forces, larger contact area). This correlates with the conclusion made in the Ref. [12] about the indentation depth as the main governing parameter of the process of friction.

However, Coulomb himself made only very general empirical generalizations ([9], Chapter II, p. 99):

"1. When sliding wood on wood without lubrication, after a fairly long duration of contact, friction force is directly proportional to normal pressure; this force increases only in the first moments of contact, after a few minutes it reaches a maximum.

2. When sliding wood on wood without lubricant at a certain speed, the friction force is also proportional to the normal pressure, but, even at its largest, is much less than that required to break the bond between the surfaces after some time of contact. For example, it is established that the force necessary to disrupt the contact between two surfaces of oak, after a few minutes of contact, refers to the force required to overcome friction when the surface moves with a certain velocity as 35:22.

3. When metal slides on metal without lubrication, the frictional force is proportional to the pressure, but its value is the same, regardless of whether they want to disturb the relationship between the surfaces after a contact time, or want to maintain a certain constant speed.

4. Results for sliding of dissimilar surfaces such as wood on metal, without lubricant, differ considerably from the previous ones, since the intensity of friction, depending on the duration of contact, slowly increases and reaches its peak after $4-5$ days, and sometimes more, while for metals it achieves the stationary value in an instant and for wood in a few minutes; this growth is so slow that the frictional resistance at very low speeds is almost the same as in contact failure by shaking or separation after 3 or $4 \mathrm{~s}$ of contact. Furthermore, for wood sliding on wood without lubricant, and for metal sliding on metal, speed does affect the friction only very weakly: In this case the friction increases as the speed increases; while the velocity increases exponentially friction increases in an arithmetic progression."

\section{Coulomb and modern engineering laws of friction}

The main contribution of Coulomb to frictional studies was that, based on a wealth of experimental data, he confirmed Amontons' law, but at the same time showed its limited nature. He studied in detail the weak dependencies of the coefficient of friction on various parameters such as normal force, sliding velocity, size of the contact as well as atmospheric conditions and showed that the friction phenomenon is too complicated to be described by one single equation. However, in some limited ranges of external parameters he managed to describe friction with two-term-equations, of which the first term was a constant and the second described a relatively weak (often logarithmic, as in the case of velocity) dependence on the parameter in question. Schematically, his approximations can be roughly reformulated in the form

$$
\mu=\mu_{0}+a \ln F_{\mathrm{N}}+b \ln v+c \ln L+\cdots
$$

where $L$ is characteristic size of the system, $v$ is the sliding velocity, and $F_{\mathrm{N}}$ is the normal force. The existence of such a dependence means that the stationary coefficient of friction (in a limited region of the parameter space) can be written as

$$
\mu=\mu_{0}+\ln \left(F_{\mathrm{N}}^{a} v^{b} L^{c}\right)
$$

thus depending only on one single variable of the form $F_{\mathrm{N}}^{a} v^{b} L^{c}$. Subsequent investigations in the following centuries have shown the correctness of these general ideas in tribological systems of various physical nature. For example, in lubricated systems, in the region of hydrodynamic lubrication, the coefficient of friction is known to be $\mu \approx 2 \sqrt{\eta v L / F_{\mathrm{N}}}$ [8], where $\eta$ is the viscosity of the lubricant and $D$ the characteristic size of the system. In this case, according to Eq. (3), we have $a=-1 / 2, b=1 / 2$ and $c=1 / 2$. Dependencies with only one "master variable" have also been found recently for elastomer friction in the frame of the Greenwood-Tabor-Grosch paradigm, i.e., the rheological nature of elastomer friction $[13,14]$. It was shown $[15,16]$ that both for macroscopically flat and macroscopically curved bodies, the coefficient of friction in a limited parameter region can be described as function of a parameter combination of the form 
$F_{\mathrm{N}}^{a} v^{b} L^{c}$, while the constants $a, b$ and $c$ may depend on the particular rheology and the form of the body.

It is important to stress that dependencies of the Eq. (2) can be used for constructing generalized laws of friction on a purely empirical basis, without any theoretical background. Indeed, as long as the weak dependences of the Eq. (2) are additive, the master curve procedure can be applied. For example, the dependence on $v$ has the same form for different normal forces and different sizes of the system and is only shifted along the $\log v$-axis. This leads to a simple procedure for constructing dependencies on all variables, which is already widely used in elastomer science to determine the rheological or frictional properties of elastomers as a function of velocity and temperature [14]. The effectiveness of this procedure in application to the velocity and normal force dependence of friction was shown experimentally in Ref. [16]. Note that similar power-law equations have also been suggested and experimentally verified for wear of materials [17].

What Coulomb did not manage to do, is a unification of static and kinetic friction. He discovered the time dependence of the static force of friction and the velocity dependence of the sliding force of friction but did not consider these dependencies to be manifestations of the same physics. This was done much later, in 1970s in the works of Dieterich $[18,19]$ and Rice and Ruina [20]. Dieterich and Ruina showed that the unification of static and kinetic friction can only be achieved by introduction of an additional internal state variable. The equations of Dieterich-Ruina look very similar to Eq. (2) but include an additional differential equation, which allows describing the processes going on in the frictional contact even without relative movement. This theoretical scheme has a very simple and robust theoretical background [21]. The concept of Dieterich and Ruina proved very successful and was confirmed for different materials in a very wide range of velocities [22].

\section{Conclusion}

First of all, we would like to stress that the simple formulation of "Coulomb's law of friction" which can be found in most textbooks - the force of friction is proportional to the normal force and does not depend on the contact area and velocity - has little to do with the real work of Coulomb. On the contrary, Coulomb found that Amontons' law, as well as the independence of the coefficient of friction on velocity, normal force, contact area and roughness are only a first, very rough approximation. He differentiated between material couples (e.g., metal-metal), where Amontons' law is a good approximation, and other (wood on metal or wood on wood), where there are significant deviations from Amontons' law. In all cases, however, the dependencies are relatively weak. In contemporary language we would say they are of logarithmic character: The geometric and loading parameters have to be changed by several orders of magnitude to achieve a change in the coefficient of friction by a factor of two. Coulomb also gives simple two-term relations, which empirically summarize these experimental findings.

Some of dependencies studied by Coulomb have also been studied in detail in subsequent years, particularly the velocity dependence of the coefficient of friction. The reason for this may be in the importance of the velocity dependence for dynamic stability of frictional systems. The explicit dependence on time (kinetics of friction) was studied since the works of Dieterich. The dependence of the coefficient of friction on the normal force is an area which only begins to develop [23, 24]. The dependence of the dry force of friction on the size of the system has not been studied systematically yet.

It could be said that Coulomb has left us a work program that the tribological community still has not yet finished. Formulating effective theoretical and empirical procedures for constructing "generalized laws of friction", including the dependencies on the normal force and the shape, remain hot topics in modern tribology.

\section{Acknowledgement}

One of the authors (V. L. P.) acknowledges discussions of the role of Coulomb in the physics of friction with participants of the International Forum on the Fundamentals of Sliding Friction and Vibration. This work was partially supported by the Ministry of Education of the Russian Federation, by Tomsk State University Academic D. I. Mendeleev Fund Program and by COST Action MP1303. 
Open Access: This article is distributed under the terms of the Creative Commons Attribution License which permits any use, distribution, and reproduction in any medium, provided the original author(s) and source are credited.

\section{References}

[1] Dowson D. In History of Tribology. London: Longman Group Limited, 1979: 678.

[2] Amontons G. De la resistance cause'e dans les machines (About resistance and force in machines). Mem l'Acedemie $R$ A: 257-282 (1699)

[3] Barber J R. Multiscale surfaces and Amontons' law of friction. Trib Lett 49: 539-543 (2013)

[4] He G, Müser M H, Robbins M O. Adsorbed layers and the origin of static friction. Science 284: 1650-1652 (1999)

[5] Stewart Gillmor C. In Coulomb and the Evolution of Physics and Engineering in Eighteenth-Century France. Princeton: Princeton University Press, 1971: 328.

[6] Coulomb C A. Sur une application des regles de maximis $\&$ minimis a quelques problemes de statique, relatifs a I' architecture. Memoires de Mathematique \& de Physique, presentes a I' Academie. Royale des Sciences par divers Savans, \& Ius dans ses Assemblees 7: 343-382 (1773)

[7] Heyman J. In Coulomb's Memoir on Statics. An Essay in the History of Civil Engineering. London: Imperial College Press, 1997: 212.

[8] Popov V L. Contact Mechanics and Friction. Physical Principles and Applications. Berlin: Springer, 2010.

[9] Coulomb C A. Theorie des machines simple (Theory of simple machines). Bachelier, Paris, 1821.

[10] Coulomb C A. Memoire sur les frottemens de la pointe des pivots. Paris, 1797: 448-471.

[11] Coulomb C A. Experiences destinees a determiner la coherence des fluides et les lois de leur resistance dans les movements

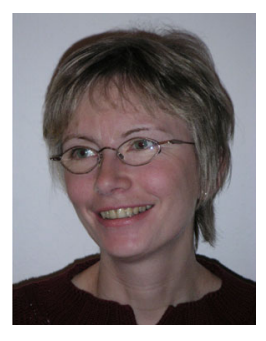

Elena POPOVA. She studied Slavistics at the Tomsk State University, Russia (graduated in 1987 with degree Dipl.-Phil.) and German literature studies and philosophy at the University of Paderborn, Germany (graduated in tre lents. Paris, 1801: 246-305

[12] Popov V L, Dimaki A, Psakhie S, Popov M. On the role of scales in contact mechanics and friction between elastomers and randomly rough self-affine surfaces. Sci Rep in press (2015)

[13] Greenwood J A, Tabor D. The friction of hard sliders on lubricated rubber-The importance of deformation losses. Proc Roy Soc London 71: 989-1001 (1958)

[14] Grosch K A. Relation between friction and visco-elastic properties of rubber. Proc Roy Soc London A 274: 21-39 (1963)

[15] Li Q, Popov M, Dimaki A, Filippov A E, Kürschner S, Popov V L. Friction between a viscoelastic body and a rigid surface with random self-affine roughness. Phys Rev Lett 111: 034301 (2013)

[16] Popov V L, Voll L, Li Q, Chai Y S, Popov M. Generalized law of friction between elastomers and differently shaped rough bodies. Sci Rep 4: 3750 (2014)

[17] Rhee S K. Wear equation for polymer sliding against metal surfaces. Wear 16: 431-445 (1970)

[18] Dieterich J H. Time dependent friction and the mechanics of stick-slip. Pure Appl Geophys 116: 790-806 (1978)

[19] Dieterich J H. Modeling of rock friction: 1. Experimental results and constitutive equations. J Geophys Res Solid Earth 84: 2161-2168 (1979)

[20] Rice J R, Ruina A L. Stability of steady frictional slipping. J Appl Mech 50: 343-349 (1983)

[21] Müser M H, Urbakh M, Robbins M O. Statistical mechanics of static and low-velocity kinetic friction. In Advance in Chemical Physics, Ed. by Prigogine I, Rice S A. John Wiley \& Sons, Inc., 2003.

[22] Grzemba B. New experimental investigations on the DieterichRuina law. Facta Universitatis, Ser Mech Eng 13(1) (2015)

[23] Otsuki M, Matsukawa H. Systematic breakdown of Amontons' law of friction for an elastic object locally obeying Amontons' law. Sci Rep 3: 1586 (2013)

[24] Rubinstein S M, Cohen G, Fineberg J. Detachment fronts and the onset of dynamic friction. Nature 430: 1005-1009 (2004)

2003 with degree Magistra Artium). She worked at the Tomsk Pedagogical University, Russian Academy of Sciences and later at the University of Potsdam. Since 2007 she coordinated double degree programs in Engineering Science with Russia and China at the Berlin University of Technology and carried out research in the field of history of tribology. 


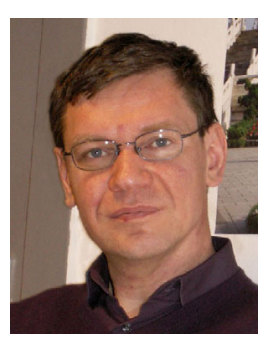

Valentin L. POPOV. He is a full professor at the Berlin University of Technology. He studied physics (1976-1982) and obtained his $\mathrm{PhD}$ degree in 1985 from the Moscow State Lomonosov University. He worked at the Institute of Strength Physics of the Russian Academy of Sciences. After a guest-professorship in the field of theoretical physics at the University of Paderborn (Germany) from 1999 to 2002, he has headed the Department of System Dynamics and the Physics of Friction in the Institute of Mechanics at the Berlin University of Technology. His areas of interest include tribology, nanotribology, tribology at low temperatures, biotribology, the influence of friction through ultrasound, numerical simulation of frictional processes, research regarding earthquakes, as well as themes relating to materials sciences such as the mechanics of elastoplastic media with microstructures, strength of metals and alloys, and shape memory alloys. He has published 30 papers in leading international journals during the past 5 years. He is the author of the book "Contact Mechanics and Friction: Physical principles and applications" which appeared in German, English, Chinese, and Russian editions. $\mathrm{He}$ is the joint editor of international journals and regularly organizes international conferences and workshops over diverse tribological themes. He is a member of the Scientific Council of the German Tribological Society. He has intensively collaborated with many industrial corporations and possesses experience in implementing the results of scientific research in industrial applications. 